
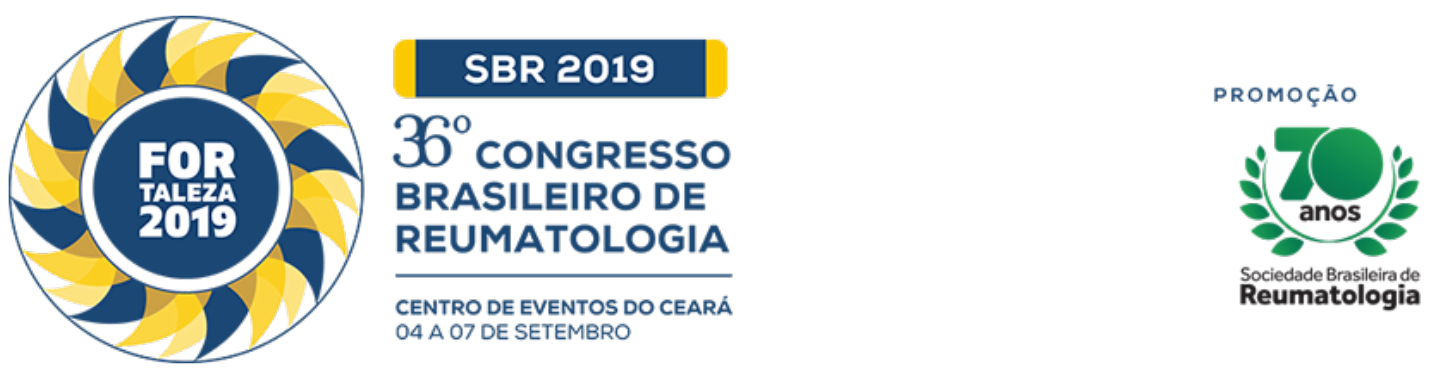

\title{
SUBACUTE SPINAL CORD SYNDROME IN A PATIENT WITH RHEUMATOID ARTHRITIS
}

Ana Júlia Furbino Dias Bicalho (UFMG, Belo Horizonte, MG, Brasil), Teresa Cristina Abreu Ferrari (UFMG, Belo Horizonte, MG, Brasil), Raquel Oliveira Guimarães (UFMG, Belo Horizonte, MG, Brasil), Clarice Garcia Valadares Xavier (UFMG, Belo Horizonte, MG, Brasil), Caio Moreira (UFMG, Belo Horizonte, MG, Brasil), Maria Raquel Costa Pinto (UFMG, Belo Horizonte, MG, Brasil), Anna Carolina Faria Moreira Gomes Tavares (UFMG, Belo Horizonte, MG, Brasil), Maria Fernanda Bandão Resende Guimarães (UFMG, Belo Horizonte, MG, Brasil)

\section{BACKGROUND}

Rheumatoid arthritis (RA) patients in immunosuppressant treatment, including novel therapies with JAK inhibitors, are in high risk of opportunistic infections, including atypical forms. Brazil still has high rates of tuberculosis (TB), and it is frequently a diagnostic challenge in this group of patients, because of unconventional clinical presentation.

\section{CASE REPORT}

54-year-old male patient, RA diagnosis in 2014, previously treated with prednisone, methotrexate, etanercept and abatacept, has being treated with tofacitinib since 2017, with good response. He was admitted in emergency room due to weakness of left lower limb associated with fever, night sweats, cough and unintentional weight loss of $15 \mathrm{kgs}$ over the last 8 months. Evolved during hospitalization with left lower limb plegia, paresis of the other leg and urinary retention. At admission nodular and crusty skin lesions on elbow extensor surfaces were seen. Chest tomography revealed mediastinal lymphadenomegaly, lithic lesions in the sternum, ribs and thoracic vertebrae. MRI showed T4 fracture with spinal cord compression. Mantoux test was 22 (previous was non reactant). Patient underwent spinal decompressive surgery and vertebral fragment biopsy showed predominantly mononuclear inflammatory infiltrate with granulomatous contour while fragment culture disclose 01 cream-colored colony of Mycobacterium sp. Mediastinal lymph node biopsy showed chronic, granulomatous, caseiform lymphadenitis with positive Acid- Fast Bacilli (AFB) test. AFB and Xpert MTB / RIF tests were negative on vertebral fragment, sputum and pleural effusion. According to national TB guidelines, treatment with rifampicin, isoniazid, pyrazinamide and ethambutol was started with an expected duration of 9 months. Until the end of treatment, control of RA-related symptoms was performed only with low doses of corticosteroids.

\section{CONCLUSION}

The AFB and Xpert MTB/ RIF tests are primarily studied for sputum analysis compared to samples from other tissues. The specificity of the AFB smear depends on the prevalence of nontuberculous mycobacteria, besides the local laboratory technical qualification - in Brazil is about $98 \%$. The test Xpert MTB / RIF is indicated for lung and laryngeal tuberculosis. The sensitivity of the test is $90 \%$ in adults. The Xpert MTB / RIF test can also be used for extrapulmonary TB diagnosis. In this case, it has lower sensitivity, so a negative result does not rule out the disease. The data for risk of TB in patients with RA using tofacitinib are still scarce. Patients should be screened for TB prior to treatment with tofacitinib. After immunosuppressive treatment, we should pay attention to possible signs of opportunistic infection. 